\title{
Chang'E-5T Orbit Determination Using Onboard GPS Observations
}

\author{
Xing Su, Tao Geng *, Wenwen Li, Qile Zhao and Xin Xie \\ GNSS Research Center, Wuhan University, 129 Luoyu Road, Wuhan 430079, China; \\ suxing_gnss@whu.edu.cn (X.S.); cheeselee@whu.edu.cn (W.L.); zhaoql@whu.edu.cn (Q.Z.); \\ xiexin@whu.edu.cn (X.X.) \\ * Correspondence: gt_gengtao@whu.edu.cn; Tel.: +86-027-6877-8767
}

Academic Editor: Assefa M. Melesse

Received: 15 April 2017; Accepted: 27 May 2017; Published: 1 June 2017

\begin{abstract}
In recent years, Global Navigation Satellite System (GNSS) has played an important role in Space Service Volume, the region enclosing the altitudes above $3000 \mathrm{~km}$ up to $36,000 \mathrm{~km}$. As an in-flight test for the feasibility as well as for the performance of GNSS-based satellite orbit determination (OD), the Chinese experimental lunar mission Chang'E-5T had been equipped with an onboard high-sensitivity GNSS receiver with GPS and GLONASS tracking capability. In this contribution, the 2-h onboard GPS data are evaluated in terms of tracking performance as well as observation quality. It is indicated that the onboard receiver can track 7-8 GPS satellites per epoch on average and the ratio of carrier to noise spectral density $(\mathrm{C} / \mathrm{N} 0)$ values are higher than $28 \mathrm{~dB}-\mathrm{Hz}$ for $90 \%$ of all the observables. The $\mathrm{C} 1$ code errors are generally about $4.15 \mathrm{~m}$ but can be better than $2 \mathrm{~m}$ with C/N0 values over $36 \mathrm{~dB}-\mathrm{Hz}$. GPS-based Chang'E-5T OD is performed and the Helmert variance component estimation method is investigated to determine the weights of code and carrier phase observations. The results reveal that the orbit consistency is about $20 \mathrm{~m}$. OD is furthermore analyzed with GPS data screened out according to different C/N0 thresholds. It is indicated that for the Chang'E-5T, the precision of OD is dominated by the number of observed satellite. Although increased C/N0 thresholds can improve the overall data quality, the available number of GPS observations is greatly reduced and the resulting orbit solution is poor.
\end{abstract}

Keywords: Chang'E-5T; orbit determination; onboard GNSS receiver; C/N0; deep space navigation

\section{Introduction}

GNSS has evolved into a more robust system in recent years and played a vital role in scientific and engineering applications. It was originally conceived to provide the terrestrial and airborne users with positioning, navigation, and timing services. Later, the services were adopted in low Earth orbit (LEO) satellites applications, such as real-time spacecraft navigation, precise orbit determination, three-axis attitude control, precise time synchronization, etc. [1-4]. The performance environment of GNSS receiver in LEO is similar to the terrestrial applications, apart from the highly dynamic effects due to orbital velocity. Based on the GPS measurements for LEO, the accuracy of LEO orbit determination has been improved to the centimeter level $[5,6]$. The service region that encloses the terrestrial users to all users up to $3000 \mathrm{~km}$ with similar service performance is termed as Terrestrial Service Volume (TSV) [7].

The region spanning the altitudes above $3000 \mathrm{~km}$ up to $36,000 \mathrm{~km}$ is considered as the Space Service Volume (SSV) [8,9]. This can be further divided into two regions: (1) the medium Earth orbit (MEO) SSV (3000 8000 km); (2) the high Earth orbit (HEO)/geostationary Earth orbit (GEO) SSV $(8000 \sim 36,000 \mathrm{~km})$. There is a widespread interest in the extension of GPS-based navigation to SSV users, because it could maximize the autonomy of a spacecraft and reduce the burden and costs of 
ground infrastructure operations. However, the use of GPS signals for SSV users, particularly for HEO/GEO missions, has special design challenges. In these missions, the GNSS receiver is at an altitude above the altitude of the GPS constellations. Consequently, the onboard GNSS receivers could only capture the side-lobe signals or main-beam signals originated from satellites on the opposite side of the Earth [10-12]. The power of side-lobe signals are generally about $20 \mathrm{~dB}$ lower than that of the main-beam ones, which would lead to the poorer observation quality [10]. The main-beam signals are 10 to 100 times weaker with limited satellite spatial diversity [13]. Moreover, the GPS satellites at high altitude, depending on the receiver sensitivity, can drastically reduce the navigation solution accuracy of SSV users, due to the very limited number of visible satellites and very poor tracking geometry for the region in the field of view [14-16]. In spite of these difficulties, specialized GNSS receivers have been designed with increased signal acquisition and weak signal tracking capabilities because of receiver technology improvements and navigation signal modernization [17], such as the Navigator GPS receiver developed at the NASA Goddard Space Flight Center [18], the TOPSTAR 3000 receiver of the European Space Agency (ESA) [19], and the low-cost GNSS system funded by the Italian Space Agency [20]. The concept of GPS tracking in SSV has actually been demonstrated by some flight experiments. For example, the EQUATOR-S spacecraft tracked a GPS satellite from an altitude of about $61,000 \mathrm{~km}$ and demonstrated the possibility of a reception of GPS side-lobe signals within a very high eccentricity orbit [21]. A GPS receiver flying on the AMSAT-OSCAR 40 (AO-40) spacecraft at a high inclination, $1000 \mathrm{~km}$ by $58,800 \mathrm{~km}$ altitude orbit, was developed to support the use of GPS for HEO experiments [22,23]. The reference orbit generated from the Two-Line Ephemeris (TLE) and the Simplified Deep-space Perturbation Version 4 (SDP4) propagator showed to be in error by about $100 \mathrm{~km}$ [24]. In addition, the possibility and feasibility to exploit GNSS navigation in lunar trajectories were also investigated and analyzed [25,26].

Chang'E 5T was launched by China National Space Administration on 24 October 2014. The mission of Chang'E 5T is lunar flyby and Earth re-entry to conduct crucial tests on capsule design planned to be used in the Chang'E-5 mission. The Chang'E-5T lunar probe is equipped with a high sensitivity GNSS receiver which could capture the GPS and GLONASS code and carrier wave signal. Fang et al. [27] firstly proved the idea of using rocket GPS measurements to determine the injected transfer orbit of Chang'E-5T. Fan et al. [28] conducted Chang'E-5T OD using onboard GPS pseudo-range measurements by dynamic method, and results showed that the position error in the one-h prediction from the OD of $1.5 \mathrm{~h}$ arc is less than $109 \mathrm{~m}$. However, the higher accuracy carrier phase measurements were not used in Fang et al. [27] or Fan et al. [28]. For the combined use of pseudo-range and carrier phase measurements in SSV, weighting approach needs to be investigated because of the lack of a priori measurement precision information compared to TSV users. In addition, the specially designed receiver was used in SSV. As an important indicator of GNSS receiver design, the C/N0 given by a receiver would affect the number of visible satellite and the quality of GNSS measurements [29], which is crucial for the OD precision.

Consequently, the GPS tracking data quality analysis and GPS-based orbit determination results for Chang'E-5T, as well as their relationship with the C/N0 are discussed in this contribution. The paper is organized as follows: In Section 2, we analyze Chang'E-5T onboard GPS data sensitivity and availability. The number of visual GPS satellites, position dilution of precision (PDOP) values and C1 code errors as a function of time and C/N0 value during the tracking arc are discussed. In Section 3, the Chang'E-5T orbit is determined using un-differenced combined observations of L1 carrier phase and the C1 code. The orbit determination period is 19:20-21:20 31 October 2014 and split into two arcs (19:20-20:50, 19:50-21:20) for the overlap arc to test the orbit consistency. Comparison between dynamic and kinematic orbit solutions is analyzed. Finally, the OD precisions with different C/N0 thresholds are discussed. 


\section{Chang'E-5T Onboard GPS Data Analysis}

Chang'E-5T lunar probe was launched at 18:00 UTC, 23 October 2014 from Xichang Satellite Launch Center of China and entered the orbit from Earth to Moon with the perigee altitude $209 \mathrm{~km}$ and apogee altitude 413,000 km. After the $196 \mathrm{~h}$ Earth-Moon-Earth flight, the probe successfully returned to Earth. The service module and the return vehicle were separated on 21:53 UTC, 31 October 2014 at the altitude of about $5000 \mathrm{~km}$ [30].

To examine the sensitivity of navigation performance during the mission of lunar exploration and availability of GNSS and to target a precise re-entry corridor in the Earth's atmosphere, a GNSS receiver capable of acquiring and tracking weak signals with high sensitivity was installed in the spacecraft. According to the flight operation schedule of Chang'E-5T mission, the GNSS receiver worked only twice, 18:56-21:53, 23 October and 18:55-21:56, 31 October. The task of Arc 1 was to demonstrate the reception of GNSS signals and to verify whether the receiver worked normally. The objective of Arc 2 was to evaluate the prediction accuracy of the separation point between the service module and the return vehicle. Unfortunately, there was a data slip in the middle of Arc 1 that lasted approximately $3 \mathrm{~min}$ [28]. As a result, the Arc 2 is chosen to be analyzed here.

The GNSS receiver could omni-directionally track GPS and GLONASS L1 phase and code observations with two antennae mounted on opposite sides of spacecraft, one of which is Earth-pointing direction and the other oriented in the zenith direction. This receiver is capable of tracking up to 24 satellites simultaneously with 24 channels. Since the GLONASS tracking data are much less and the accuracies are poorer than that of GPS [28], we didn't introduce the contribution of GLONASS in Chang'E-5T OD. The data collected by the receiver include the carrier phase, pseudo-range, Doppler and C/N0 measurement of L1 band in Receiver Independent Exchange Format (RINEX) 2.0 format. Table 1 provides some information about this receiver.

Table 1. Primary parameters of the Chang'E-5T space-borne GNSS receiver.

\begin{tabular}{cc}
\hline Parameters & Design Parameter \\
\hline Compatible frequency & GPS L1 and GLONASS L1 \\
Original observation types & carrier phase, pseudo-range, Doppler and C/N0 \\
Number of channels & 16 for GPS, 8 for GLONASS \\
Sampling rate & $3 \mathrm{~s}$ for ascent arc, $1 \mathrm{~s}$ for return arc \\
Acquisition sensitivity threshold & $29 \mathrm{~dB}-\mathrm{Hz}$ \\
Tracking sensitivity threshold & $26 \mathrm{~dB}-\mathrm{Hz}$ \\
GNSS Antenna & 2, quadrifilar helix, earth-pointing and the opposite direction \\
\hline
\end{tabular}

\subsection{Onboard GPS Data}

As shown in Figure 1, during the return periods, the receiver was able to acquire and track at least 22 GPS satellites. In most of time, the signals from eight GPS satellites were tracked simultaneously. The length of continuous tracking periods of four GPS satellites are near two hs, for instance Pseudo Random Noise (PRN) G11, G21, G22 and G32.

Figure 2 shows the measured signal levels of all the GPS satellites during the returning arc. It should be noted that the original $\mathrm{C} / \mathrm{N} 0$ values were recorded in integers. The variations of $\mathrm{C} / \mathrm{N} 0$ are very significant, approximately $25 \mathrm{~dB}-\mathrm{Hz}$ peak-to-peak. For PRN G16, G19 and G27, the C/N0 values were basically larger than $35 \mathrm{~dB}-\mathrm{Hz}$ because the Chang'E-5T probe was in the coverage of their main-beam signals; while the line-of-sight of the probe pierced the ionosphere and troposphere, i.e., GPS occultation, the $\mathrm{C} / \mathrm{N} 0$ values dropped dramatically. Figure 3 is a statistic histogram of all the $\mathrm{C} / \mathrm{N} 0$. The $\mathrm{C} / \mathrm{N} 0$ values are mainly concentrated between $28 \mathrm{~dB}-\mathrm{Hz}$ and $35 \mathrm{~dB}-\mathrm{Hz}$, much smaller than those of terrestrial and low earth orbit receivers. Even though the designed tracking sensitivity threshold of the GNSS receiver is $26 \mathrm{~dB}-\mathrm{Hz}$, there are also about four hundred observations weaker than the thresholds. 


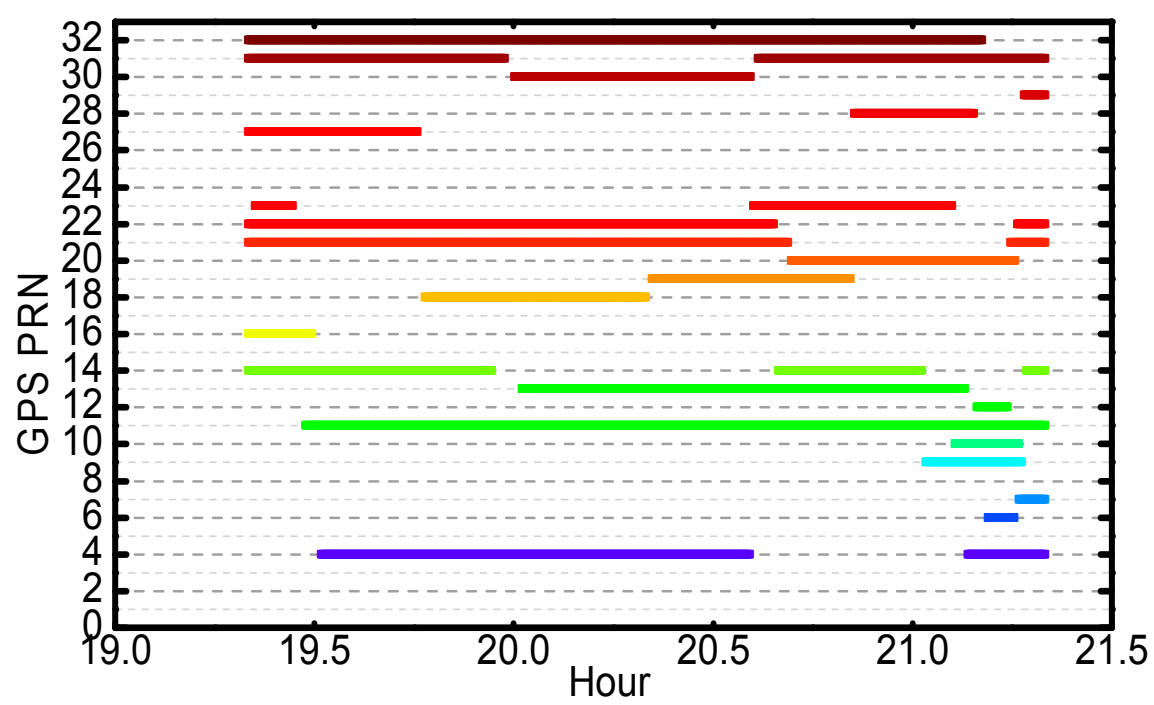

Figure 1. GPS satellites tracked by Chang'E-5T onboard receiver on 31 Octomber 2014.

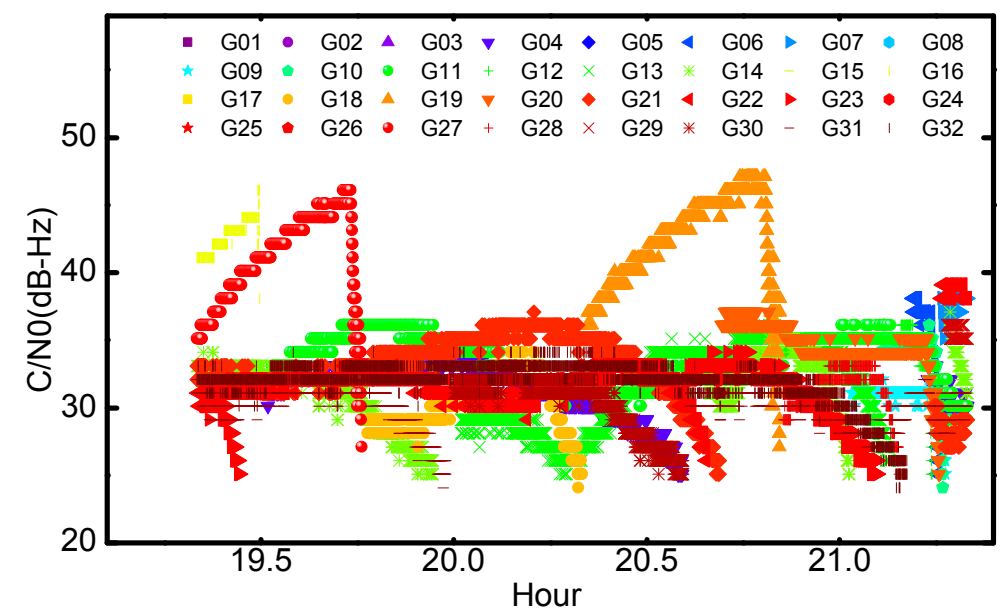

Figure 2. The measured signal level of GPS Satellites: C/N0 (unit: dB-Hz).

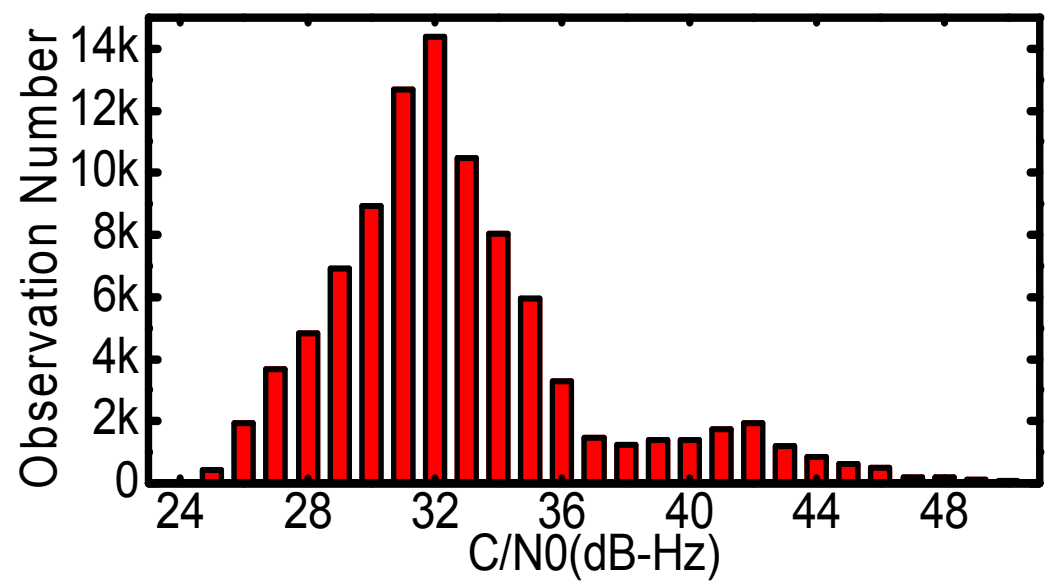

Figure 3. The number of observations with different C/N0 (unit: dB-Hz). 


\subsection{Number of Visual GPS Satellites and PDOP}

The C/N0, an important indicator of GNSS receiver design, would affect the number of visible satellite. Figure 4 shows the number of visible GPS satellites with respect to spacecraft altitude and different $\mathrm{C} / \mathrm{N} 0$ thresholds, and only the GPS observations with C/N0 values larger than the threshold are utilized in calculations. The $\mathrm{C} / \mathrm{N} 0$ thresholds are set as $24,28,31$ and $34 \mathrm{~dB}-\mathrm{Hz}$, respectively. During the returning experiment arc, the altitude fell from $50,000 \mathrm{~km}$ to $20,000 \mathrm{~km}$. The average number of tracked GPS satellites is 7.8 when the threshold of $24 \mathrm{~dB}-\mathrm{Hz}$ is taken into account. Increasing the signal tracking threshold to $31 \mathrm{~dB}-\mathrm{Hz}$, the average number decreased to 6.1. Finally, an increase of the threshold from $31 \mathrm{~dB}-\mathrm{Hz}$ to $34 \mathrm{~dB}-\mathrm{Hz}$ witnessed a significant decrease of the average number of visible GPS satellites to 2.2 .

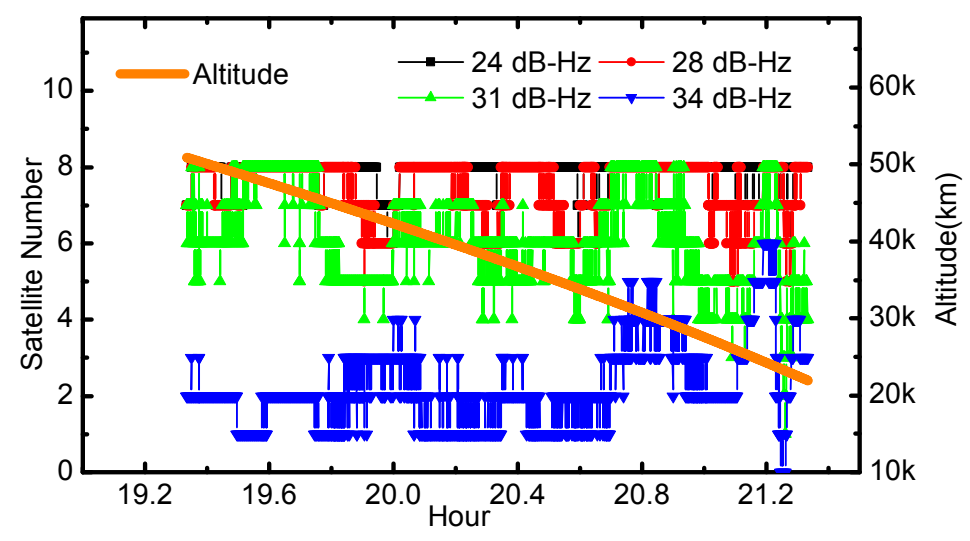

Figure 4. The number of observed GPS satellites with respect to C/N0. The orange line represents the corresponding altitudes of the flight arc, which are the distances from Chang'E-5T to the Earth center.

PDOP reveals the geometry strength between the receiver and GNSS transmitters. Usually, small PDOP value indicates good geometry condition. The PDOP variations against different $\mathrm{C} / \mathrm{N} 0$ thresholds are also investigated and shown in Figure 5. Since the PDOP could only be derived with simultaneously tracked signals from at least four GPS satellites, the threshold of $34 \mathrm{~dB}-\mathrm{Hz}$ led to quite few results, most of which were near the earth. When the $\mathrm{C} / \mathrm{N} 0$ thresholds are set as $31 \mathrm{~dB}-\mathrm{Hz}$ and $34 \mathrm{~dB}-\mathrm{Hz}$, the PDOP values can even reach over 50 in some epochs and thus are not displayed in the plot. For the case of Chang'E-5T, the PDOP values are greatly affected by the altitudes. The main reason is that GPS satellites can be observed with better spatial distribution from the receiver antenna when the spacecraft is in the lower altitudes, indicating better geometry condition.

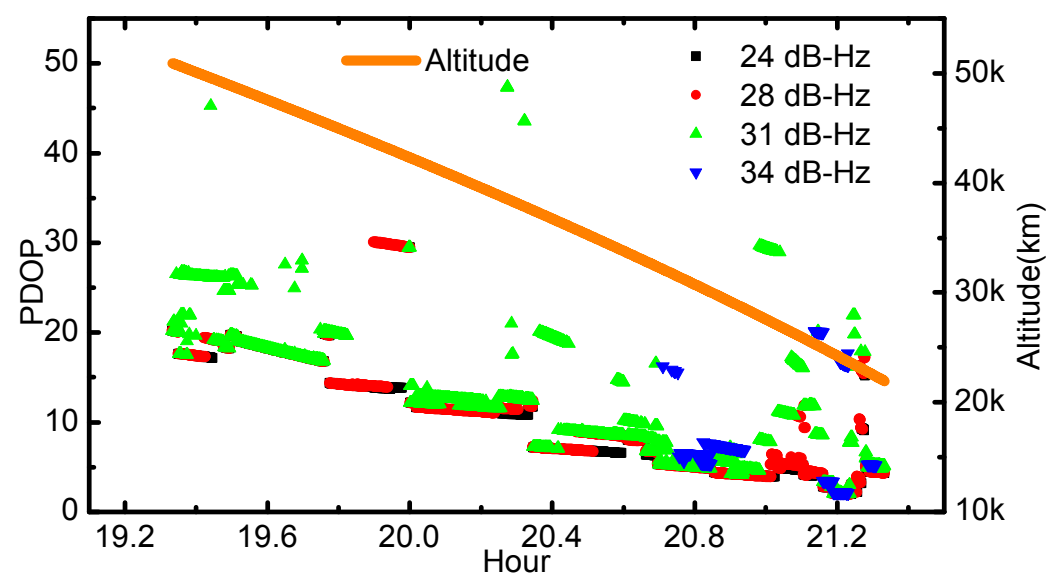

Figure 5. PDOP values time series according to the different $\mathrm{C} / \mathrm{N} 0$ thresholds. The orange line represents the altitudes of the Chang'E-5T with respect to the Earth center. 


\subsection{C1 Code Errors}

For onboard GPS signals of Chang'E-5T, most of them are ionospheric-free and tropospheric-free. It should be mentioned that only $0.2 \%$ of all the signals are affected by the atmosphere which originated from GPS satellites on the opposite part of the Earth, and excluded for computing code multipath and noise. Hence the differences between the L1 and C1 measurements used in this section include only L1 ambiguities, L1 multipath errors and noise, as well as C1 multipath errors and noise. After removing the constant ambiguities by subtracting the mean value of the differences between the L1 and C1 measurements, the residual series are dominated by the code multipath and noises since the carrier phase multipath and carrier phase noises are much smaller in magnitude. In the following the residual series is referred as $\mathrm{C} 1$ code errors and is used to assess the precision of $\mathrm{C} 1$ code observations.

The $\mathrm{C} 1$ code errors for all GPS satellites are calculated and shown in Figure 6 . In the figure the $\mathrm{C} 1$ code errors are shifted by $20 \mathrm{~m}$ from one to another. The code errors are mainly between $\pm 10 \mathrm{~m}$ and show consistent variations during the entire $2 \mathrm{~h}$. In order to show more details of onboard GPS code measurement errors, we also plot the times series of C1 code errors for G32 satellite in Figure 7. The mean value and standard deviation of G32 code errors are $0 \mathrm{~m}$ and $3.92 \mathrm{~m}$, respectively.

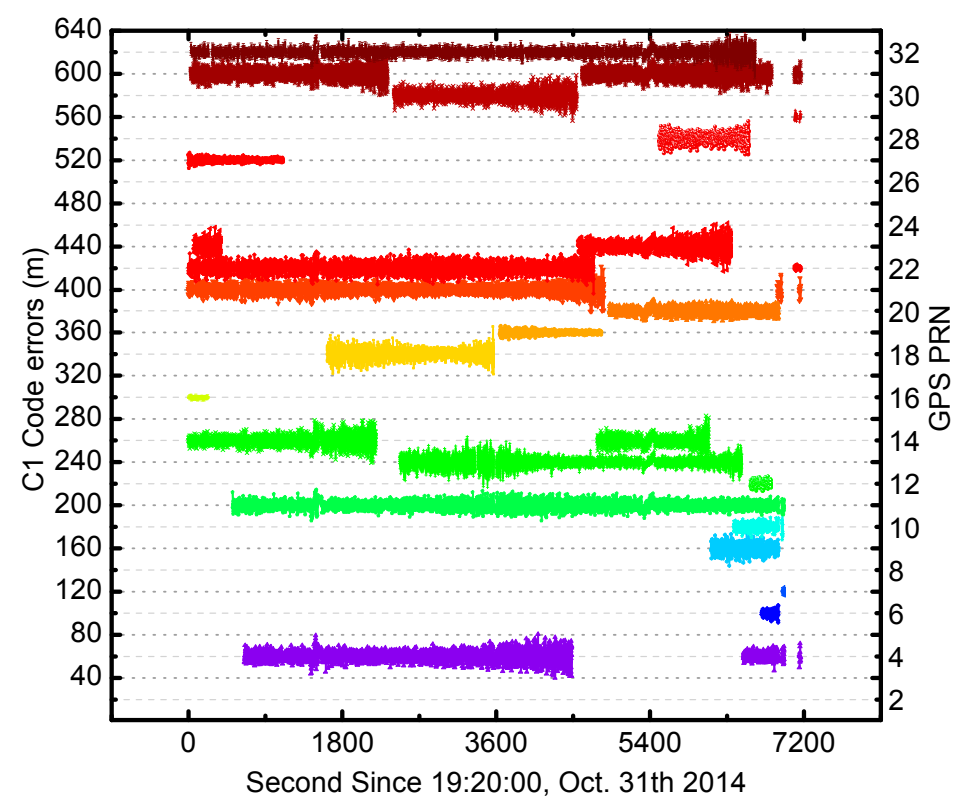

Figure 6. The times series of C1 code errors for all GPS satellites (unit: meter). The values of each satellite have been offset $20 \mathrm{~m}$ for clarity. The different colors represent different satellites, and the colors are the same as Figure 1.

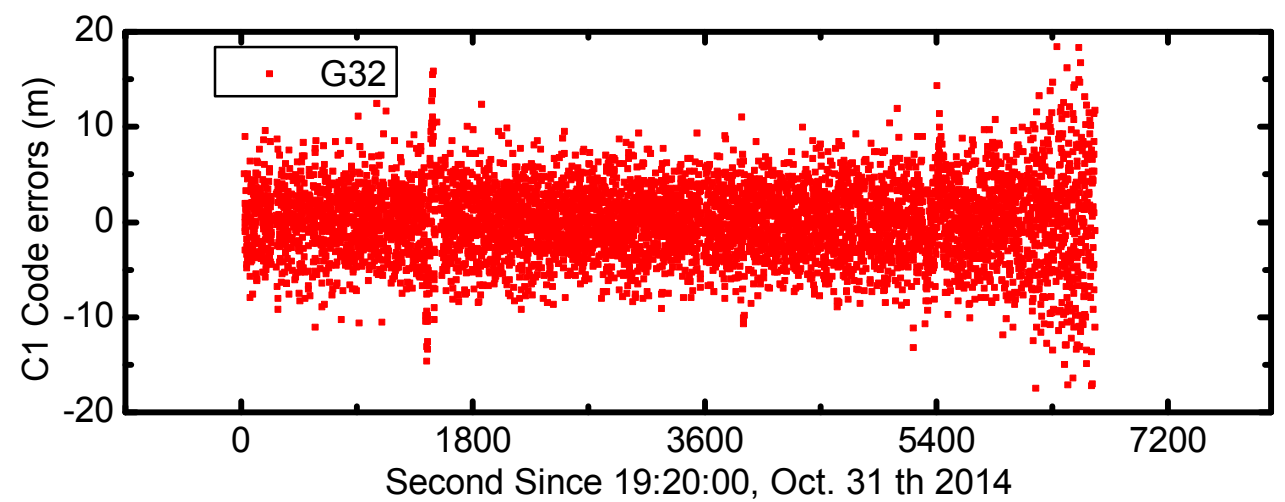

Figure 7. The times series of C1 code errors for G32 satellite (unit: meter). 
In addition, to analyze the relationship between code errors and C/N0 values, the Root Mean Squares (RMS) values of $\mathrm{C} 1$ code errors as a function of $\mathrm{C} / \mathrm{N} 0$ are shown in Figure 8. We can see that the precision of $\mathrm{C} 1$ observations is better with $\mathrm{C} / \mathrm{N} 0$ values increasing. The $\mathrm{C} 1$ code errors reach to as large as $10 \mathrm{~m}$ when $\mathrm{C} / \mathrm{N} 0$ gets close to the lower limit of the receiver sensitivity. For $\mathrm{C} / \mathrm{N} 0$ larger than $30 \mathrm{~dB}-\mathrm{Hz}$, the $\mathrm{C} 1$ observation errors are better than $5 \mathrm{~m}$. The overall precision of $\mathrm{C} 1$ code errors is $4.15 \mathrm{~m}$.

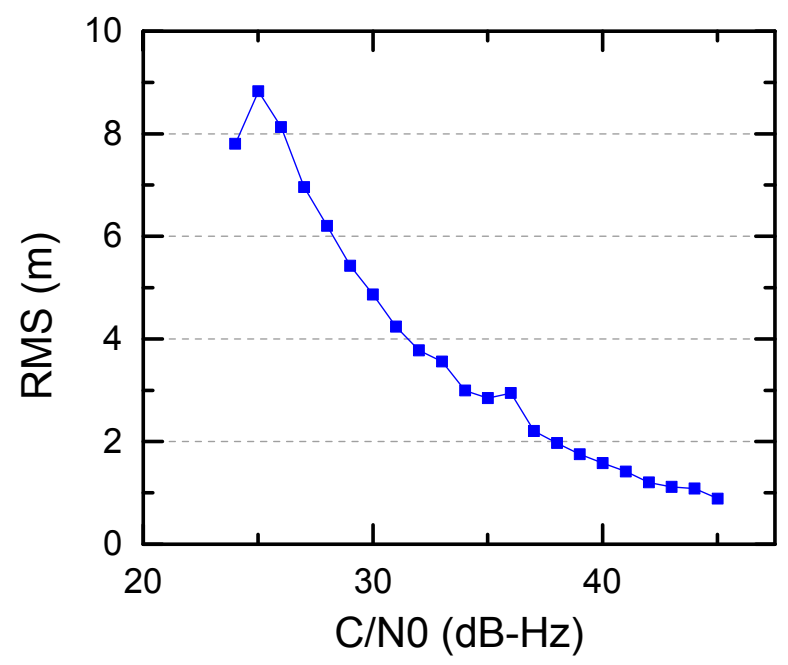

Figure 8. $\mathrm{C} 1$ code errors as a function of $\mathrm{C} / \mathrm{N} 0$.

\section{Chang'E-5T Orbit Determination}

In this section, the orbit determination strategy is presented in detail, and the orbit estimates of Chang'E-5T are evaluated.

\subsection{Processing Strategy}

The modified version of Position and Navigation Data Analyst (PANDA) software package [31] developed by GNSS Research Center of Wuhan University is employed to conduct Chang'E-5T orbit determination in this study. Table 2 summarized the observation models, dynamical models and estimated parameters. The entire 2-h GPS L1 and C1 data, sampled at $3 \mathrm{~s}$, starting from 19:20:00, 31 October 2014 is processed in a batch mode. It is noted that the Helmert variance component estimation method [32] is employed to determine the weights of code and carrier phase observations. The International GNSS Service (IGS) final orbit and $30 \mathrm{~s}$ clock offsets products are employed to bring high-precision coordinate and time frame. The phase-windup errors and relativistic effects are corrected using theoretical equations or empirical models. The igs08.atx antenna calibrations are used for the GPS satellites phase center offset (PCO) and phase center variation (PCV) corrections [33]. The receiver PCO and PCV are not considered as they are not available. The non-spherical gravity perturbations are computed by EIGEN_GL04C gravity model with degree and order of 50. The JPL DE405 ephemeris is used to calculate the N-body perturbations, while the solar radiation pressure is calculated using the Extended CODE Orbit Model (ECOM). The Chang'E-5T initial state vector, dynamic parameters, receiver clock errors as well as ambiguities are estimated during OD. The corresponding orbit solutions are called dynamic orbits.

The initial orbits of Chang'E-5T are obtained by Standard Point Positioning (SPP) using C1 code observations. The polynomial fitting method is used to detect outliers and cycle slips in L1 carrier-phase as well as C1 code measurements [34]. The post-fit residuals are also analyzed to detect minor cycle slips. 
Table 2. Observation models, dynamic models and estimated parameters for Chang'E-5T OD.

\begin{tabular}{cc}
\hline Items & Models \\
\hline Estimator & Least-squares estimation \\
\hline Observations selection & GPS L1 and C1 \\
\hline Sampling rate & $3 \mathrm{~s}$ \\
\hline Phase-windup effect & Phase polarization effects applied \\
\hline $\begin{array}{c}\text { GPS Satellite antenna phase center model } \\
\text { (PCO and PCV) }\end{array}$ & Corrected using GPS values \\
\hline GPS Satellite orbit & Fixed in IGS final orbit \\
\hline GPS Satellite clock & Fixed in IGS final 30 s interval clock \\
\hline Chang'E-5T Receiver clock & Estimated as random walk process \\
\hline Precession and nutation & IAU 2000 precession and nutation model \\
\hline EOP parameters & Polar motions and UT1 from IERS C04 series aligned to ITRF 2008 \\
\hline Troposphere and Ionosphere & None \\
\hline Geopotential (static) & IERS Conventions 2003 [35] \\
\hline $\begin{array}{c}\text { Solid earth tide/Ocean tide/Solid earth } \\
\text { pole tide/Relativistic effect }\end{array}$ & ECOM model 5-parameter with no initial value [36] \\
\hline M-body gravity & Real constant value for each ambiguity arc \\
\hline Solar radiation pressure model &
\end{tabular}

\subsection{Orbit Determination}

\subsubsection{Residual Analysis}

For the entire 2-h arc OD results, the post-fit L1 and C1 residuals are firstly analyzed to evaluate the quality of estimated Chang'E-5T orbits. As seen in Table 2, most of the observation errors have been corrected during the OD process. Hence, large post-fit residuals often reflect poor observation modeling as well as poor orbit estimation. The L1 and C1 residuals are shown in Figure 9a,b respectively. The L1 residuals from several satellites show significant linear variations with respect to epochs, and can reach $60 \mathrm{~cm}$, which may be due to carrier phase noise variations as a function of C/N0 [29] or imperfect observation models. The RMS errors of the post-fit $\mathrm{L} 1$ and $\mathrm{C} 1$ residuals are $74 \mathrm{~mm}$ and $4.6 \mathrm{~m}$ respectively, and the RMS of $\mathrm{C} 1$ residuals is consistent with that of $\mathrm{C} 1$ code errors presented in Section 2.3.

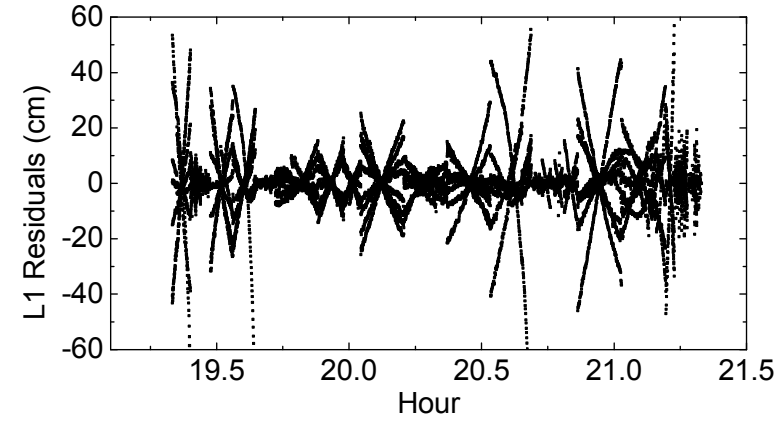

(a)

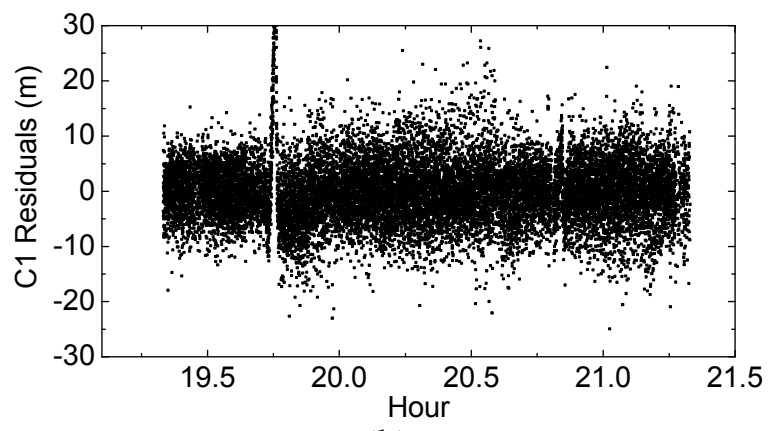

(b)

Figure 9. (a) L1 observation residual series (unit: centimeter); (b) C1 observation residual series (unit: meter). 


\subsubsection{Orbit Overlap Comparison}

To evaluate dynamic orbit, we first separate the 2-h GPS data into two 1.5-h arcs with a 1-h overlap, as shown in Figure 10. These two arcs are processed with the same OD strategy presented in Section 3.1, and their orbit differences during the overlaps are calculated in along-track, cross-track and radial components and are used as indicators of the orbit quality. The overlap comparison here can reveal the internal consistency of the orbit estimates. Figure 11 shows the 1-h overlap differences. The differences in along-track and radial components are mainly within $\pm 20 \mathrm{~m}$ but show larger discrepancies in the last $10 \mathrm{~min}$. Comparatively, the orbit differences in cross-track component are much smaller. The RMS errors in along-track, cross-track and radial direction are $10.60 \mathrm{~m}, 2.26 \mathrm{~m}$ and $13.89 \mathrm{~m}$, respectively. This indicates that the orbit consistency using the OD scheme presented in Table 2 should be at this precision.

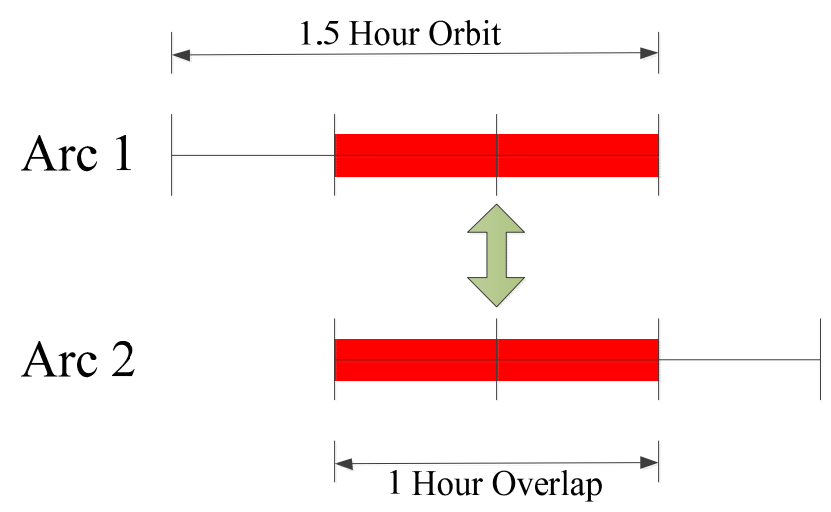

Figure 10. Orbit overlap comparison strategy.

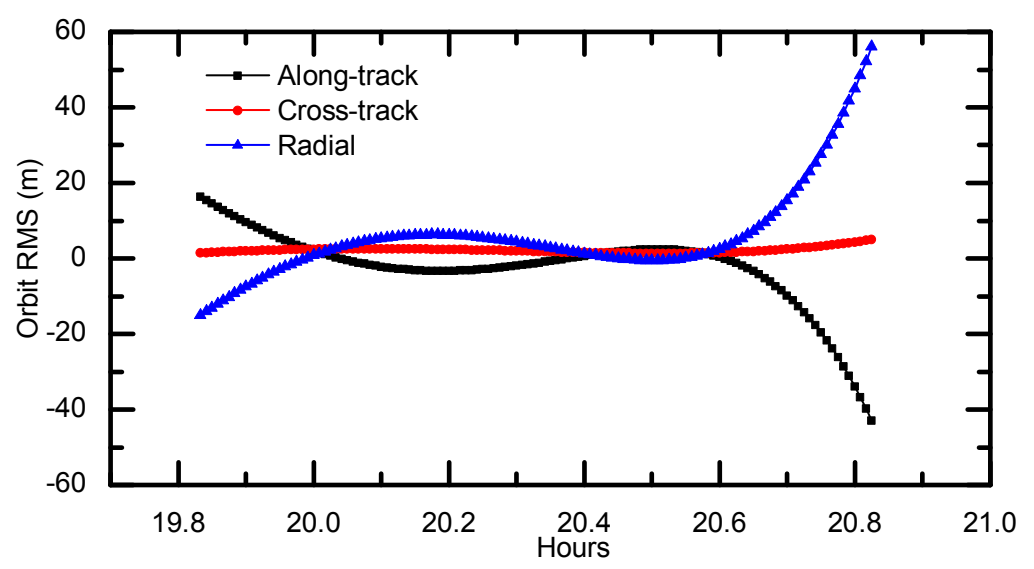

Figure 11. Orbit overlap comparison in radial, cross-track and along-track directions (unit: meter).

\subsection{Kinematic and Dynamic Orbit Comparison}

There are typically two methods for GNSS-based spacecraft OD, i.e., dynamic and kinematic method. The dynamic method can generally obtain better orbit accuracy due to the constraint of dynamic models. While the kinematic method estimates the satellite's position coordinates epoch-by-epoch and requires no a priori knowledge of the spacecraft motion [37]. The kinematic approach can be applied to a wide range of situations and is of particular interest for maneuvering spacecraft and reentry vehicles due to its purely geometrical nature. Moreover, the computational complexity is significantly reduced compared to the dynamical filtering technique.

The kinematic orbit of Chang' $\mathrm{E}-5 \mathrm{~T}$ is also calculated in this study using the $\mathrm{C} 1$ code ranges by SPP approach. The differences between the kinematic orbits and the dynamic orbits can also reveal 
the quality of the orbit solutions. Ideally, the dynamic orbits are considered of higher accuracy as the carrier-phase observations are used in addition to the code ranges. Their differences are depicted in Figure 12. As shown, the differences show significant correlations with respect to the PDOP values, which is dominated by the spacecraft altitude. The kinematic orbit precision is roughly at $90 \mathrm{~m}$ level on average and can reach $50 \mathrm{~m}$ when the altitude reaches $20,000 \mathrm{~km}$. This precision is consistent with the results from [28], which were obtained by OD using C1 code ranges combined with ground-tracking measurements.

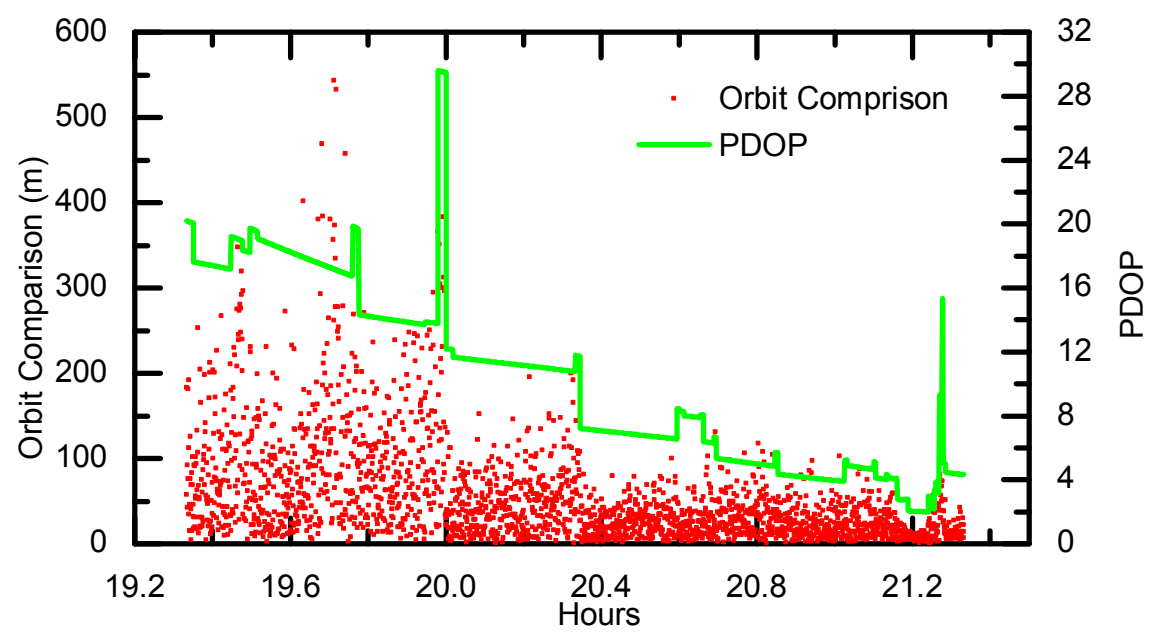

Figure 12. The SPP 3-Dimension (3D) precision and PDOP series.

\subsection{Orbit Determination with Different C/NO Thresholds}

In this section, we investigate the Chang'E-5T OD precision with different C/N0 thresholds, and the resultant orbits are compared with dynamic orbits. The orbit differences in along-track, cross-track, radial components are shown in Figure 13 and their RMS are listed in Table 3.

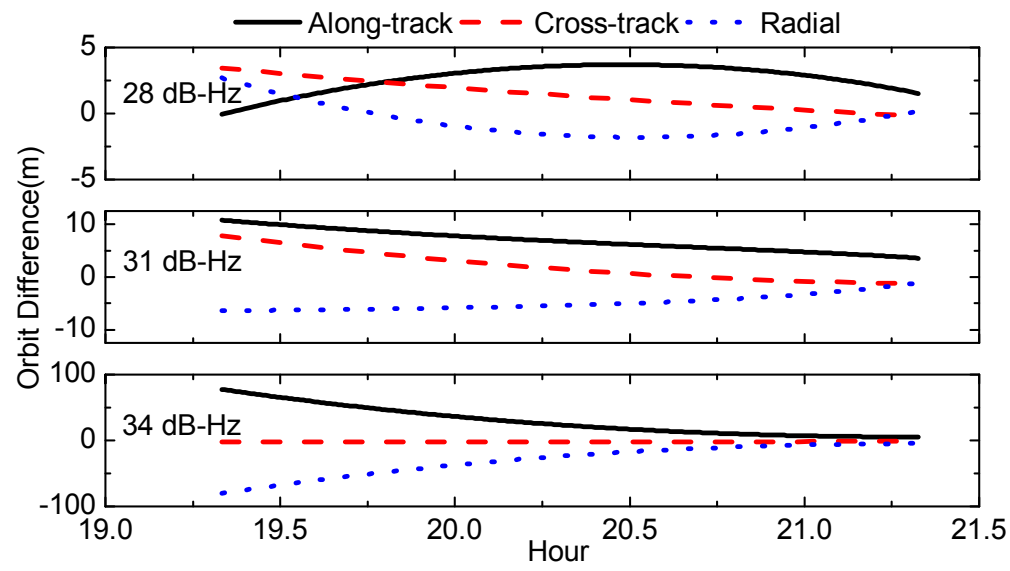

Figure 13. Orbit comparison solutions with different $\mathrm{C} / \mathrm{N} 0$ thresholds in radial, cross-track and along-track directions (unit: meter).

Table 3. Orbit Precision of different C/N0 thresholds (unit: meter).

\begin{tabular}{ccccc}
\hline C/N0 & Along-Track & Cross-Track & Radial & 3D \\
\hline 28 & 2.86 & 1.77 & 1.34 & 3.62 \\
31 & 7.15 & 3.35 & 5.08 & 9.39 \\
34 & 36.03 & 2.21 & 36.93 & 51.65 \\
\hline
\end{tabular}


It can be indicated that with lower C/N0 threshold, better orbit precision can be obtained. This can be primarily attributed to the number of visible GPS satellites decrement due to C/N0 threshold increment. When the $\mathrm{C} / \mathrm{N} 0$ threshold is raised to $34 \mathrm{~dB}-\mathrm{Hz}$, the number of visible GPS satellites per epoch is around 2 as indicated in Section 2.1. This results in particularly low observation redundancy, and makes it more difficult for estimation convergence. Hence, for this case the orbit errors are as large as $80 \mathrm{~m}$ at the beginning and then converge slowly to smaller values; the overall 3D RMS errors are $50 \mathrm{~m}$. However, for the other two cases, their orbit differences are both below $10 \mathrm{~m}$ in 3D RMS.

\section{Conclusions}

The 2-h onboard GPS data collected by Chang'E-5T probe are explored and analyzed in this contribution. The observation quality, mainly including the number of observed satellite, C/N0 level, PDOP as well as $\mathrm{C} 1$ code errors are evaluated in detail. It is found that on average the onboard GNSS receiver can track 7-8 GPS satellites per epoch for Chang'E-5T. For over 71.6\% of the observations, their $\mathrm{C} / \mathrm{N} 0$ values are higher than $31 \mathrm{~dB}-\mathrm{Hz}$, and for $31.8 \%$ over $34 \mathrm{~dB}-\mathrm{Hz}$. The PDOP values are significantly related to the spacecraft altitude, reaching about 20 at 50,000 km altitude and better than 10 below $30,000 \mathrm{~km}$. Since the C1 and L1 observations are almost free from the ionosphere and troposphere delays, the $\mathrm{C} 1$ code error is calculated by differencing the $\mathrm{C} 1$ and $\mathrm{L} 1$ observations directly while the $\mathrm{L} 1$ ambiguities is removed by averaging. The resultant overall $\mathrm{C} 1$ code errors are $4.15 \mathrm{~m}$. For $\mathrm{C} 1$ observations with higher $\mathrm{C} / \mathrm{N} 0$ levels, i.e., $36 \mathrm{~dB}-\mathrm{Hz}$, the precision can be better than $2 \mathrm{~m}$. Although increased C/N0 threshold can improve overall data quality and produce smaller code errors, the available number of GPS observation is greatly reduced and the resulting PDOP values are increased.

OD is carried out for Chang'E-5T using the C1 and L1 observations and the Helmert variance component estimation method is investigated to determine the weights of code and carrier phase observations. The OD precision is firstly evaluated by overlap comparison, which indicates an orbit consistency is about $17 \mathrm{~m}$ in 3D RMS. The RMS of L1 and C1 residuals are $74 \mathrm{~mm}$ and $4.58 \mathrm{~m}$, respectively, showing good consistency with the $\mathrm{C} 1$ code errors statistics. Furthermore, the OD precision is analyzed by screening GPS data with different C/N0 thresholds of $28 \mathrm{~dB}-\mathrm{Hz}, 31 \mathrm{~dB}-\mathrm{Hz}$ and $34 \mathrm{~dB}-\mathrm{Hz}$. The results indicate that the OD precision for Chang' $\mathrm{E}-5 \mathrm{~T}$ is mainly dominated by the number of visible GPS satellites. For the cases of C/N0 thresholds of $28 \mathrm{~dB}-\mathrm{Hz}$ and $31 \mathrm{~dB}-\mathrm{Hz}$, the orbit differences are below $10 \mathrm{~m}$. However, higher $\mathrm{C} / \mathrm{N} 0$ threshold of $34 \mathrm{~dB}-\mathrm{Hz}$ results in significant orbit precision degradation to $51 \mathrm{~m}$, which should be primarily due to data volume decrement. Therefore, we suggest that the received $\mathrm{C} / \mathrm{N} 0$ minimum should be designed to be less than $31 \mathrm{~dB}-\mathrm{Hz}$ for onboard receiver in SSV, preferably less than $28 \mathrm{~dB}-\mathrm{Hz}$.

We need to further research in some aspects to improve the accuracy and autonomy of navigation architectures in future lunar exploration missions for the various mission phases. First, comprehensive utilization of GPS, GLONASS, BeiDou and Galileo system should be taken into account to improve OD accuracy by increasing the number of available satellites and reducing PDOP values. In addition, the integration of GNSS with other state-of-the-art space navigation sensors like IMU and Doppler radar altimeter is expected to achieve a high degree of autonomy and robustness of navigation. Second, a receiver with higher performance, particularly the capability of receiving weak signals, should be developed to provide GNSS navigation to the lunar explorers at the distance of 400,000 km and even farther in deep space. Third, the data processing algorithm should be adopted to further improve the accuracy and autonomy of navigation solutions using existing and future GNSS signals, such as real-time enhanced filtering and weak signal and low C/N0 data processing algorithms.

Acknowledgments: This research is partially supported by the National Natural Science Foundation of China (Grant Nos. 41674004, 41404032, 41574030), the Fundamental Research Funds for the Central Universities (No. 2042016kf0185) and the Natural Science Foundation of Hubei Province (2014CFB168).

Author Contributions: Xing Su performed the experiments and wrote the article. Tao Geng provided the initial idea for this study and supervised the article. Wenwen Li wrote the article. Qile Zhao supervised the experiments. Xin Xie prepared and analyzed the data and drew figures. 
Conflicts of Interest: The authors declare no conflict of interest.

\section{References}

1. Kang, Z.; Tapley, B.; Bettadpur, S.; Ries, J.; Nagel, P.; Pastor, R. Precise orbit determination for the GRACE mission using only GPS data. J. Geod. 2006, 80, 322-331. [CrossRef]

2. Bock, H.; Jäggi, A.; Švehla, D.; Beutler, G.; Hugentobler, U.; Visser, P. Precise orbit determination for the GOCE satellite using GPS. Adv. Space Res. 2007, 39, 1638-1647. [CrossRef]

3. Montenbruck, O.; Ramos-Bosch, P. Precision real-time navigation of LEO satellites using global positioning system measurements. GPS Solut. 2007, 12, 187-198. [CrossRef]

4. Montenbruck, O.; Hauschild, A.; Andres, Y.; von Engeln, A.; Marquardt, C. (Near-)real-time orbit determination for GNSS radio occultation processing. GPS Solut. 2012, 17, 199-209. [CrossRef]

5. Jäggi, A.; Hugentobler, U.; Bock, H.; Beutler, G. Precise orbit determination for GRACE using undifferenced or doubly differenced GPS data. Adv. Space Res. 2007, 39, 1612-1619. [CrossRef]

6. Bock, H.; Jäggi, A.; Beutler, G.; Meyer, U. GOCE: Precise orbit determination for the entire mission. J. Geod. 2014, 88, 1047-1060. [CrossRef]

7. Bauer, F.H.; Moreau, M.C.; Dahle-Melsaether, M.E.; Petrofski, W.P.; Stanton, B.J. The GPS Space Service Volume. In Proceedings of the 14th International Technical Meeting of the Satellite Division of The Institute of Navigation (ION GPS 2001), Salt Lake City, UT, USA, 11-14 September 2001; pp. 2503-2514.

8. Bauer, F.H. GNSS Space Service Volume \& Space User Data Update. In Proceedings of the International Committee for GNSS 10th Meeting, Boulder, CO, USA, 1-6 November 2015.

9. Miller, J.J.; Bauer, F.H.; Oria, A.J.; Pace, S.; Parker, J.J.K. Achieving GNSS Compatibility and Interoperability to Support Space Users. In Proceedings of the 29th International Technical Meeting of The Satellite Division of the Institute of Navigation (ION GNSS+ 2016), Portland, OR, USA, 12-16 September 2016.

10. Czopek, F.M. Description and Performance of the GPS Block I and II L-Band Antenna and Link Budget. In Proceedings of the 6th International Technical Meeting of the Satellite Division of The Institute of Navigation (ION GPS 1993), Salt Lake City, UT, USA, 22-24 September 1993; pp. 37-43.

11. Geng, T.; Su, X.; Zhao, Q. MEO and HEO Satellites Orbit Determination Based on GNSS Onboard Receiver. In Proceedings of the China Satellite Navigation Conference (CSNC) 2012, GuangZhou, China, 15-19 May 2012; pp. 223-234.

12. Unwin, M.; Steenwijk, R.D.V.V.; Blunt, P.; Hashida, Y.; Kowaltschek, S.; Price, S.R. Navigating Above the GPS Constellation-Preliminary Results from the SGR-GEO on GIOVE-A. In Proceedings of the 26th International Technical Meeting of The Satellite Division of the Institute of Navigation (ION GNSS+ 2013), Nashville, TN, USA, 16-20 September 2013; pp. 3305-3315.

13. Ramakrishnan, S.; Reid, T.; Enge, P. Leveraging the L1 Composite Signal to enable autonomous navigation at GEO and beyond. In Proceedings of the 26th International Technical Meeting of The Satellite Division of the Institute of Navigation (ION GNSS+ 2013), Nashville, TN, USA, 16-20 September 2013; pp. 3336-3346.

14. Ruiz, J.L.; Frey, C.H. Geosynchronous Satellite Use of GPS. In Proceedings of the 18th International Technical Meeting of The Satellite Division of the Institute of Navigation (ION GNSS 2005), Long Beach, CA, USA, 13-16 September 2005; pp. 1227-1232.

15. Force, D.A.; Miller, J.J. Combined Global Navigation Satellite Systems in the Space Service Volume. In Proceedings of the International Technical Meeting 2013, San Diego, CA, USA, 27-29 January 2013.

16. Rathinam, A.; Dempster, A.G. Effective utilization of space service volume through combined GNSS. In Proceedings of the 29th International Technical Meeting of The Satellite Division of the Institute of Navigation (ION GNSS+ 2016), Portland, OR, USA, 12-16 September 2016.

17. Guasch, J.R.; Weigand, R.; Risueño, G.L.; Silvestrin, P. AGGA-4-Core device for GNSS space-receivers of the next decade. In Proceedings of the NAVITEC, Noordwijk, The Netherlands, 10-12 December 2008; pp. 1-8.

18. Lulich, T.D.; Bamford, W.A.; Winternitz, L.M.B.; Price, S.R. Results from Navigator GPS Flight Testing for the Magnetospheric MultiScale Mission. In Proceedings of the 25th International Technical Meeting of the Satellite Division of the Institute of Navigation (ION GNSS 2012), Nashville, TN, USA, 17-21 September 2012; pp. 731-742. 
19. Mehlen, C.; Laurichesse, D. Real-time GEO orbit determination using TOPSTAR 3000 GPS receiver. In Proceedings of the 13th International Technical Meeting of the Satellite Division of the Institute of Navigation (ION GPS 2000), Salt Lake City, UT, USA, 19-22 September 2000; pp. 1985-1994.

20. Zin, A.; Scotti, M.; Mangolini, E.; Cappelluti, I.; Fiordiponti, R.; Amalric, J.; Flament, P.; Brouillard, E.; Kowaltschek, S. Preparing an autonomous, low-cost GNSS positioning and timing function on board a GEO telecom mission: A study case. CEAS Space J. 2015, 7, 247-262. [CrossRef]

21. Balbach, O.; Eissfeller, B.; Hein, G.W.; Enderle, W.; Schmidhuber, M.; Lemke, N. Tracking GPS above GPS satellite Altitude: First Results of the GPS Experiment on the HEO Mission Equator-S. In Proceedings of the IEEE PLANS 1998, Savannah, GA, USA, 11-16 April 1998; pp. 243-249.

22. Moreau, M.C.; Bauer, F.H.; Carpenter, J.R. Preliminary Results of the GPS Flight Experiment on the High Earth Orbit AMSAT-OSCAR 40 Spacecraft. In Proceedings of the 25th Annual AAS Guidance and Control Conference, Breckenridge, CO, USA, 6-10 February 2002; pp. 1-15.

23. Moreau, M.C.; Davis, E.P.; Carpenter, J.R.; Kelbel, D.; Davis, G.W.; Axelrad, P. Results from the GPS Flight Experiment on the High Earth Orbit AMSAT OSCAR-40 Spacecraft. In Proceedings of the 15th International Technical Meeting of the Satellite Division of The Institute of Navigation (ION GPS 2002), Portland, OR, USA, 24-27 September 2002; pp. 122-133.

24. Davis, G.; Moreau, M.; Carpenter, R.; Bauer, F. GPS-Based Navigation and Orbit Determination for AMSAT AO-40 Satellite. In Proceedings of the AIAA Guidance, Navigation, and Control Conference and Exhibit, Monterey, CA, USA, 5-8 August 2002.

25. Palmerini, G.B.; Sabatini, M.; Perrotta, G. En route to the Moon using GNSS signals. Acta Astronaut. 2009, 64, 467-483. [CrossRef]

26. Capuano, V.; Botteron, C.; Leclère, J.; Tian, J.; Wang, Y.; Farine, P.-A. Feasibility study of GNSS as navigation system to reach the Moon. Acta Astronaut. 2015, 116, 186-201. [CrossRef]

27. Fang, H.; Zhang, R.; Wang, J.; Wang, D.; Guo, H. Injected transfer orbit determination of lunar probe Chang'E $5 \mathrm{~T} 1$ using short-arc rocket GPS measurements. Adv. Space Res. 2015, 56, 1726-1736. [CrossRef]

28. Fan, M.; Hu, X.; Dong, G.; Huang, Y.; Cao, J.; Tang, C.; Li, P.; Chang, S.; Yu, Y. Orbit improvement for Chang'E-5T lunar returning probe with GNSS technique. Adv. Space Res. 2015, 56, 2473-2482. [CrossRef]

29. Hartinger, H.; Brunner, F.K. Variances of GPS Phase Observations: The SIGMA- $\varepsilon$ Model. GPS Solut. 1999, 2, 35-43. [CrossRef]

30. Cao, J.; Zhang, Y.; Hu, S.; Tang, G.; Li, X. Orbit determination for CE5T based upon GPS data. Syst. Eng. Electron. 2016, 38, 1121-1125.

31. Shi, C.; Zhao, Q.; Hu, Z.; Liu, J. Precise relative positioning using real tracking data from COMPASS GEO and IGSO satellites. GPS Solut. 2013, 17, 103-119. [CrossRef]

32. Kusche, J. A Monte-Carlo technique for weight estimation in satellite geodesy. J. Geod. 2003, 76, $641-652$. [CrossRef]

33. Rebischung, P.; Griffiths, J.; Ray, J.; Schmid, R.; Collilieux, X.; Garayt, B. IGS08: The IGS realization of ITRF2008. GPS Solut. 2011, 16, 483-494. [CrossRef]

34. Guo, X.; Zhang, Q.; Zhao, Q.; Guo, J. Precise Orbit Determination for LEO Satellites Using Single-frequency GPS Observations. Chin. Space Sci. Technol. 2013, 33, 41-46.

35. McCarthy, D.D.; Petit, G. IERS Conventions (2003); Bundesamt fuer Kartographie und Geodaesie: Frankfurt am Main, Germany, 2003.

36. Springer, T.A.; Beutler, G.; Rothacher, M. A new solar radiation pressure model for GPS. GPS Solut. 1999, 2, 50-62. [CrossRef]

37. Bisnath, S.; Langley, R. High-precision, kinematic positioning with a single GPS receiver. In Proceedings of the 14th International Technical Meeting of the Satellite Division of The Institute of Navigation (ION GPS 2001), Salt Lake City, UT, USA, 11-14 September 2001; pp. 161-170.

(C) 2017 by the authors. Licensee MDPI, Basel, Switzerland. This article is an open access article distributed under the terms and conditions of the Creative Commons Attribution (CC BY) license (http:/ / creativecommons.org/licenses/by/4.0/). 